\title{
ACCEPTABILITY AND EFFECTIVENESS OF A BREAST HEALTH AWARENESS PROGRAMME FOR RURAL WOMEN IN INDIA
}

\author{
R. S. P. RAO, N. SUMA, N. S. NAIR, V. G. KAMATH
}

\section{ABSTRACT}

BACKGROUND: Breast cancer being one of the leading cancers among women in developing countries, prevention or identification of the disease at an early stage is of paramount importance in saving as well as improving the quality of life. Breast health awareness appears to be a pragmatic method for this.

Objective: To determine the acceptability and effectiveness of an educational intervention programme on breast health awareness for rural women by trained female health workers. SETTINGS AND DESIGN: Community based nonrandomised educational intervention study carried out over a period of 1 year. Three hundred and sixty rural women in the age group 30-59 years were randomly selected (and age-wise stratified), from a coastal village in Southern India. METHODS: Women were educated on breast health and breast self-examination by specifically trained health workers and their awareness and proficiency levels were evaluated at the end of 1 and 3 months postintervention. STATISTICAL ANALYSIS: This was done using the Statistical Package for Social Sciences Version 10. RESULTS: Following the educational intervention, a significant increase in overall awareness regarding breast cancer $(z=-$ $15.807 ; \mathrm{P}<0.001)$ as well as in the performance of self-examination of the breast 321 / 342 (93\%) was observed. Forgetfulness or being too busy appeared to be the two most frequently perceived barriers. CONCLUSION: This study clearly shows that a community oriented educational intervention programme emphasizing on proper technique can bring about the desirable behavioural change among women.

KEY WORDS: acceptability of breast health awareness programme

Breast cancer among Indian women is the second most common cancer after cervix and is already the leading cancer in certain metros. ${ }^{[1]}$ Approximately 80000 cases are estimated to occur annually; the age adjusted incidence rates varying between 16 and 25/ 100000 population. ${ }^{[2]}$ Statistics also show that locally advanced breast cancer constitutes more than $50-70 \%$ of patients presenting for

Department of Community Medicine, Kasturba Medical College, Manipal, Karnataka, India treatment. ${ }^{[3]}$ Lack of awareness regarding the disease coupled with nonaffordability or nonavailability of facilities for early detection and treatment are some of the major determinants of this.

Mammography is currently considered to be the forerunner in early detection. However, in a country like India wherein awareness regarding the disease is itself abysmal and

Correspondence

Dr. Suma Nair

Assistant Professor, Kasturba Medical College, Manipal, Karnataka - 576104, India E-mail:

sunsaag1030@yahoo.co.in / uma.nair@manipal.edu 
with considerable resource crunch health promotion activities need to be considered before embarking on anything else. A breast health awareness campaign could therefore be an important intervention in this direction. This can be carried out by specifically trained female health workers instead of physicians thereby ensuring cost effectiveness.

Although the role of regular self-examination in prevention of breast cancer mortality has been debated, ${ }^{[4]}$ it can nevertheless be utilised in enhancing breast awareness among women. In fact regular self-examination has been suggested as a part of the overall breast health promotion concept. ${ }^{[5]}$ The teaching of breast self examination (BSE) can help women to know the structure and composition of their normal breasts thereby enhancing their sensitivity to any abnormality at the earliest.

The objectives of this study were to use trained female health workers to educate rural women on breast health in order to, increase their awareness regarding breast cancer, carry out proficient self-examination of the breast, seek medical care at the earliest when necessary as well as identify barriers if any to selfexamination.

\section{METHODS}

This was a community-based nonrandomised educational intervention study carried out over a period of 1 year from January to December 2003. The study was conducted at the rural field practice area of a teaching institution, which covers a population of 45000 spread over 11 villages of a Taluk in a Southern State of India.
The village that was selected for this study had a total population of 8680 of which $51 \%$ were females. The study population comprised of 1796 women in the age group 30-59 years and they constituted $40 \%$ of the total female population. Considering this was an exploratory study, unsure about its feasibility and acceptability and moreover being conducted for the first time in the field practice area, it was decided to recruit 300 women in the age group 30-59 years. Expecting a drop out of $15 \%$, a sample of 360 women was selected by the stratified random sampling technique.

Six auxilliary nurse midwives (ANMs) from the field practice area were educated on breast cancer and trained in breast examination skills using a comprehensive lesson plan. Two training sessions of $4 \mathrm{~h}$ each were conducted on two consecutive days. The training methods included didactic lecture followed by interactive sessions. Audio visual aids such as chalk and blackboard, charts, posters, over-head projector, and CD ROMs were used. Additionally the trainees were encouraged to practice the skills learnt on a breast model at the clinical skills laboratory. This was followed by a micro teaching session by the ANMs simulating the training sessions to be conducted in the field and deficiencies if any were corrected.

Each ANM was assigned a sector of the village and she was responsible for motivating and training 60 women from that sector. Willingness to participate in the study was obtained by a verbal consent from the women after explaining the objectives of the study.

\section{PRETEST}

The training sessions were conducted for a group of 10-15 women under the supervision of the investigator. Prior to initiation of the training, information pertaining to sociodemographic characteristics of the women and their baseline awareness regarding breast cancer, its risk factors, available screening modalities, and BSE was obtained using a structured questionnaire. The questionnaire also included the revised Udai Pareekh scale for the assessment of socio-economic status.

\section{Interventions}

The health worker briefed the women about breast cancer and followed it up with a demonstration of BSE stressing on thoroughness and the recommended technique. Women were taught the mirror method for visual inspection of the breast and the lying down position for breast palpation. Tactile skills were emphasized using an indigenous breast model. Women were instructed to do self-examination on a daily basis for the first 1 month and on a weekly basis for the next so as to familiarise themselves with their breasts. Thereafter monthly BSE was advised depending on their menstrual status.

The education was followed by an interactive session with the trainer to clarify doubts. At the end of the session an illustrated booklet on the topic was distributed among the women, with an intention to reinforce what was taught.

\section{Post-test}

Evaluation was carried out by a house-tohouse visit by the investigator at 1 - and 3- month intervals postintervention. A post-test questionnaire was administered to evaluate the awareness levels. Competence in carrying out self examination was assessed with respect to: self reported frequency of performance (daily, weekly, or monthly), observer rated proficiency scores for technique and completeness of self examination as well as lump detection scores in a breast model. A modified Stillman scale for beliefs on the value of BSE was used to identify barriers among those not performing self-examination.

The data was analysed using the Statistica Package for Social Sciences (SPSS) Version 10. Summary tables were presented in terms of percentages and Mc Nemar's as well as Wilcoxon signed rank test were used to calculate statistical significance.

\section{RESULTS}

\section{Participants}

Of the 360 women enrolled into the study, 342 were available for the final analysis (response rate, $90 \%$ ). Three-fourths (14) of the women lost to follow up were in the older age group (50-59 years), and one-fourth (8) of them were illiterate.

Table 1 shows the baseline characteristics of the women in the study. Interestingly of the low proportion of women $56 / 342$ (16.4\%), who claimed to be familiar with BSE none of them had ever practiced it; $6 / 342$ (11\%) had received some form of training from a local NGO and the rest had sourced their knowledge from either the television or the print media. 
Table 1: Baseline characteristics of women at entry into breast awareness study

\begin{tabular}{|c|c|c|}
\hline Characteristics & Number & Percentage \\
\hline \multicolumn{3}{|l|}{ Age } \\
\hline $30-39$ & 190 & 55.6 \\
\hline $40-49$ & 86 & 25.1 \\
\hline $50-59$ & 66 & 19.3 \\
\hline \multicolumn{3}{|l|}{ Educational level } \\
\hline illiterate & 62 & 18.1 \\
\hline $1-10$ years of schooling & 258 & \\
\hline 311 years of schooling & 22 & 6.4 \\
\hline \multicolumn{3}{|l|}{ Occupation } \\
\hline Housewife & 217 & 63.5 \\
\hline Unskilled & 111 & 32.5 \\
\hline Skilled & 08 & 2.3 \\
\hline White collar & 06 & 1.7 \\
\hline \multicolumn{3}{|l|}{ Religion } \\
\hline Hindu & 287 & 84.0 \\
\hline Muslim & 33 & 9.6 \\
\hline Christian & 22 & 6.4 \\
\hline \multicolumn{3}{|l|}{ Marital status } \\
\hline Single & 21 & 6.1 \\
\hline Married & 295 & 86.3 \\
\hline Widowed & 25 & 7.3 \\
\hline Separated & 01 & 0.3 \\
\hline \multirow{2}{*}{\multicolumn{3}{|c|}{ Socio economic status }} \\
\hline & & \\
\hline Middle & 138 & 40.4 \\
\hline High & 05 & 1.4 \\
\hline Known family history of & 07 & 2.0 \\
\hline Known personal history & 04 & 1.2 \\
\hline $\begin{array}{l}\text { of breast disease } \\
\text { Ever familiar with BSE * }\end{array}$ & 56 & 16.4 \\
\hline Ever performed BSE* & 00 & 00 \\
\hline
\end{tabular}

Breast self-examination.

\section{Effect of intervention}

The total awareness score for each study subject was calculated based on their response to six knowledge based questions pertaining to the risk factors for breast cancer, the importance of early detection, available screening modalities and frequency of BSE. The pretest and post-test awareness scores [Figure 1] illustrated a significant increase in overall awareness regarding breast cancer and the various aspects pertaining to it $(z=-15.807$;
$P<0.001)$. All the same, less number of women even after education, were aware of risk factors for breast cancer $31 / 342(9 \%)$ during the pre-test and 165/342 (48\%) during posttest.

Irrespective of their socio-demographic status women were willing to be educated by the health worker and the educational intervention was acceptable to them. Nearly $321 / 342(93 \%)$ of the women performed BSE following the intervention [Table 2]. A slight decline in frequency of performance $321 / 342(93.9 \%)$ vs $306 / 342$ (89.5\%) was observed over the next 3 months. This was predominantly among older women who were married, with 10 years or less of schooling, multiparous, and belonging to the middle Socio-economic strata (SES).

Attitude to BSE and health seeking behaviour The number of women professing to barriers in carrying out BSE [Table 3] increased from $22 / 342(6.4 \%)$ in the first post-test to nearly 40 / $342(11.6 \%)$ in the second. The most

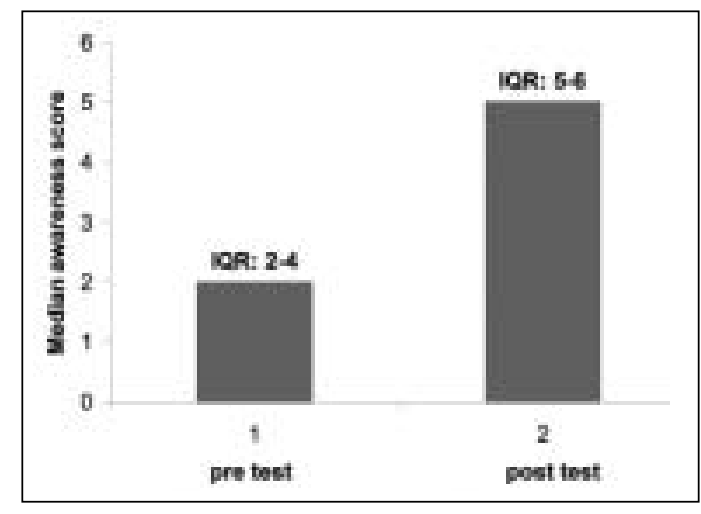

Figure 1: Effect of intervention on breast health wareness. 1 and 2 - pretest and post-test median awareness scores in a scale of 6 .

Table 2: Continuity in performance of breast self-examination (BSE) according to socio-demographic characteristics $(n=342)$

\begin{tabular}{|c|c|c|c|c|}
\hline \multirow[b]{2}{*}{ Socio demographic characteristics } & \multicolumn{3}{|c|}{ Women ever performing* BSE } & \multirow[b]{2}{*}{$\begin{array}{l}\text { Mc Nemar's test } \\
\text { (P value) }\end{array}$} \\
\hline & $N$ & $\begin{array}{l}\text { Post-test } 1[1 \text { month } \\
\text { post-training] } \mathrm{n}(\%)\end{array}$ & $\begin{array}{l}\text { Post-test } 2[3 \text { months } \\
\text { post-training] n (\%) }\end{array}$ & \\
\hline $30-39$ & 190 & $182(95.7)$ & $172(90.5)$ & 0.118 \\
\hline $40-49$ & 86 & $80(93)$ & $81(94)$ & 1.000 \\
\hline $50-59$ & 66 & $59(89.3)$ & $53(80.3)$ & 0.070 \\
\hline \multicolumn{5}{|l|}{ Religion } \\
\hline Hindu & 287 & $271(94.4)$ & $260(90.5)$ & 0.043 \\
\hline Muslim & 33 & $29(87.8)$ & $26(78.7)$ & 0.375 \\
\hline Christian & 22 & $21(95.4)$ & $20(90.9)$ & 1.000 \\
\hline \multicolumn{5}{|l|}{ Educational status } \\
\hline Illiterate & & $56(90.3)$ & $57(91.9)$ & 1.000 \\
\hline $1-10$ years of schooling & 258 & $243(94.1)$ & $227(87.9)$ & 0.004 \\
\hline 11 years of schooling & 22 & $22(100)$ & $22(100)$ & - \\
\hline \multicolumn{5}{|l|}{ Socio-economic status } \\
\hline Low & 199 & $186(93.4)$ & $180(90.4)$ & 0.180 \\
\hline Middle & 138 & $130(94.2)$ & $121(87.6)$ & 0.049 \\
\hline High & 5 & $5(100)$ & $5(100)$ & - \\
\hline \multicolumn{5}{|l|}{ Marital status } \\
\hline Single & 21 & $20(95.2)$ & $17(80.9)$ & 0.250 \\
\hline Married & 295 & $278(94.2)$ & $265(89.8)$ & 0.019 \\
\hline Widowed & 25 & $22(88)$ & $23(92)$ & 1.000 \\
\hline Separated & 1 & $1(100)$ & $1(100)$ & - \\
\hline \multicolumn{5}{|l|}{ Parity } \\
\hline Nulliparous & 39 & $35(89.7)$ & $34(87.1)$ & 1.000 \\
\hline Single parity & 46 & $46(100)$ & $42(91.3)$ & 0.125 \\
\hline Multiparous (2) & 257 & $240(93.3)$ & $230(89.4)$ & 0.052 \\
\hline
\end{tabular}

${ }^{*}$ Ever perform: those who have performed BSE on a daily, weekly, or monthly basis

frequently perceived barrier was forgetfulness or being too busy. Older women believed it to be unnecessary.

Majority $296 / 342(86.5 \%)$ of the women endorsed that they would seek immediate help in case of detection of any breast lump and approach either a doctor or a health worker. However, an additional 43/342 (12.6\%) felt it worthwhile to wait for a while and look for any further changes prior to seeking help.

\section{DISCUSSION}

Consistent with the economic and social changes in the country women in India are increasingly marrying late with a subsequent increase in the age at first child birth and low parity. This has enhanced the risk of developing breast cancer than ever before. Among the several options available for early detection of breast cancer in India, creating awareness appears to be an important prerequisite.

Table 3: Barriers to breast self-examination $(n=40)$ Barriers

\begin{tabular}{ll} 
Barriers & Number (\%) \\
\hline Embarrassment & $3(7.5)$ \\
Lack of privacy & $1(2.5)$ \\
Lack of confidence & $1(2.5)$ \\
Fear of finding some abnormality & $2(5.0)$ \\
Time consuming and cumbersome & $19(47.5)$ \\
Not at risk hence not required to do & $13(32.5)$ \\
Forgets to do & $19(47.5)$ \\
\hline
\end{tabular}


Considering the acute shortage of doctors in rural areas in this country, it is appropriate and necessary to train ANMs or female health workers. This is possible as demonstrated by this study, wherein the female health workers were trained and they in turn, were successful in creating awareness among the rural women regarding breast cancer as well as motivating them to competently perform BSE, in order to get acquainted with their breasts.

Various studies have shown the effectiveness of interventions in increasing the knowledge about breast cancer, it's risk factors, awareness of screening for breast cancer, and BSE. ${ }^{[6-8]}$ Although statistics from developed countries suggest better compliance for physician conducted educations, ${ }^{[0]}$ the present study shows a high acceptance of health workers as educators. This is probably due to the better rapport that they have with the community especially the women.

A previous study from India revealed deficient knowledge and practice of BSE even among educated Indian women and the present study concurs with these findings ${ }^{[10]} A$ similar scenario has been noticed in other developing countries as well. ${ }^{[11]}$ In contrast $90 \%$ of the women in the developed world are aware of BSE; nonetheless the practice varies from 15 to $40 \% .{ }^{[12]}$

The barriers to BSE noted in our study were similar to the ones reported elsewhere. ${ }^{[11],[13]}$ Nevertheless, the negative psychological impact of BSE such as fear was acknowledged by a very small proportion of women [Table 3]. The apparent nonchalance among older women reflects a cultural ethos specific to rural
India. They were of the opinion that having led a relatively disease free life so far, they were unlikely to get the disease now, and therefore felt it unnecessary to comply with the intervention.

Although the effectiveness of BSE remains controversial, ${ }^{[14]}$ it nevertheless has its own merits. Involuntarily it brings about an increased awareness among women, empowering them to take care of their own health as well as inducing them to seek medical attention at the earliest.

An apparent limitation of our study is the generalisability; considering that the rural women in this study had a high-literacy rate, it is likely that the results are generalisable to similar settings. Compliance among older women was another problem and this probably implies the need for an age-specific intervention. Furthermore, limited aspects pertaining to the beliefs of the participants were investigated; therefore the possibility of having missed certain issues of greater concern cannot be ruled out.

This study does not answer whether heightened awareness regarding breast health leads to early detection and better prognosis. However, before trying to answer this question, it is important to establish an appropriate method to create this awareness.

\section{CONCLUSION}

The results of this study suggest that, BSE could be used as a strategy for creating breast health awareness among rural women.
Additionally, female health workers could be trained to create this awareness and instruct women to carry out BSE proficiently. A systematic review on this topic could probably throw more light in this direction.

\section{ACKNOWLEDGMENT}

Mrs. Diana Noronha and Mrs. Neelavathy for their contributions as well as all the study subjects for their co-operation.

\section{REFERENCES}

1. Indian Council of Medical Research. National Cancer Registry Programme of India - an Overview. NCRP: Bangalore; 2002.

2. Nair MK, Sankaranarayanan R, Nair KS, Amma NS, Varghese C, Padmakumari G, et al. Overall survival from breast cancer in Kerala, India, in relation to Menstrual, Reproductive, and Clinical factors. Cancer 1993;71:1791-6.

3. Chopra R. The Indian scene. J Clin Onco 2001;19:106S-11S.

4. Hackshaw AK, Paul EA. Breast self examination and death from breast cancer: a Meta Analysis. Br J Cancer 2003;88:1047-53.

5. Plesnicar A, Kovac V, Kralj B. Breast cancer and breast health awareness as an evolving health promotion concept. Radiol Oncol 2004;38:27-34.

6. Devi R, Singh MM, Kumar R, Walia I. An effective manual on breast self-examination. World Health
Forum 1998:19:388-9.

7. Kuhns-Hastings J, Brakey MR, Marshall IA Effectiveness of a comprehensive breast cancerscreening class for women residing in rural areas. Appl Nurs Res 1993;6:71-9.

8. Wood RY, Duffy ME, Morris SJ, Carnes JE. The effect of an educational intervention on promoting breast self-examination in older African American and Caucasian women. Oncol Nurs Forum 2002;29:1081-90.

9. Bennett SE, Lawrence RS, Fleischmann $\mathrm{KH}$ Gifford CS, Slack WV. Profile of women practicing Breast Self Examination. JAMA 1983;249:488-91.

10. Drakshyani DK, Venkata RP. Teacher's knowledge and practice of Breast Self Examination. Indian J Med Sci 1994;48:284-7.

11. O'Malley MS, Fletcher SW. US preventive services task force. Screening for breast cancer with breast self examination. A critical review. JAMA 1987;257:2196-203.

12. Friedman LC, Nelson DV, Webb JA, Hoffman LP, Baer PE. Dispositional optimism, self efficacy, and health beliefs as predictors of Breast Self Examination. Am J Prev Med 1994;10:130-5.

13. Jarvandi S, Montazeri A, Harirchi I, Kazemnejad A. Beliefs and behaviours of Iranian teachers toward early detection of breast cancer and breast self examination. Public Health 2002;116:245-9.

14. Larkin M. Breast self examination does more harm than good says task force. Lancet 2001;357:2109. 